\title{
IJSEM at SGM, 5 years on
}

\section{Aidan Parte, Managing Editor, IJSEM}

IJSEM (formerly IJSB) is now well into its fifth year under the stewardship of the Society for General Microbiology. There have been significant changes to the format and scope of the journal over that time, particularly with regards to the submission of papers dealing with unicellular eukaryotes. We have published a number of papers in 2001 from the International Society for Evolutionary Protistology's meeting in Ceské Budějovice in August 2000, and we have also published two important papers from Tom Cavalier-Smith concerning the evolution of all microorganisms. The protistologists have also provided some wonderful cover pictures for the journal. In the last year, there have been several major developments on the journal, and I will outline them below.

\section{Online submission}

Since June 2001, nearly one-half of all papers submitted to the journal have been via the ESPERE online submission and peer review system. As many of you will know, either as authors or reviewers, the system involves the author submitting a PDF (portable document format) file of their paper to a secure website. The Editorial Office is notified of the submission by e-mail, and we then forward the paper's details, including an encrypted URL for the PDF file, to the chosen Editor, who forwards the URL to his chosen referees. This means that a paper can be under consideration by reviewers within hours of submission. The potential time savings for authors based in North America, Asia or Australia are enormous: for example, an author in Japan could submit a paper via normal airmail and it could take up to a week to reach us; then within a few days it could be despatched to an Editor in Australia, only to arrive a week or so later. The Editor could then choose expert referees back in Europe, and the paper then travels halfway around the world again. Imagine the time saving, and reduced costs to the author and SGM, had the paper been submitted via ESPERE!

\section{Online report form}

To complement ESPERE, we have developed an online referee report form (http://www.sgm.ac.uk/ Form/ijsref.htm), which can also be used for conventional submissions. This saves a lot of time in transmitting the report to the Editor and the referee can be confident that the report has reached the Editor because a confirmation message appears on-screen as soon as the report has been sent. The Editor has the simple task of copying the relevant sections of the report into an e-mail message for the author.

\section{'Papers in press' and publish ahead of print}

Another development is the 'papers in press' listing on our website. As anyone who has seen the list will know, it is a very long page, and covers all papers that have been accepted, are awaiting proofing or awaiting assignment to an issue. The staff at SGM and the Editorial Board of IJSEM are well aware of the delays facing authors of accepted papers. We would all like to publish every paper shortly after acceptance. However, owing to the enormous increase in submissions and high acceptance rate of papers, a backlog has built up. Why not publish 4000 pages a year, then? Well, although it would be nice for the authors, there are insufficient institutional subscribers to fund such an expansion in page numbers; the only viable alternative would be page charges, and these are not under consideration at present. Since SGM took over the journal from the ASM, the page numbers have doubled - the governing council of SGM has supported the journal very generously over this time, but it could not contemplate sustaining large financial losses indefinitely. We are now in a situation where the journal is breaking even and will be allowed to grow in a controlled, financially balanced, manner depending on subscription income.

The 'papers in press' list also incorporates our new 'publish ahead of print' scheme. This involves authors of accepted papers sending a PDF file of the accepted version of their paper, including figures and tables, to the Editorial Office; then, once we have received a signed copyright assignment form (also a PDF file on our website!), we 'stamp' the PDF with the date of online publication, a copyright line and the DOI digital object identifier. The DOI is a unique number that will remain with the paper in perpetuity but will always 'resolve' to the definitive version of the paper in IJSEM Online - you may have noticed the DOI in the top right-hand corner of the title page of every paper in this issue. What this publishing industry standard means is that a paper can be published online, and cited, several months in advance of the publication of the printed journal. We hope that authors will appreciate the benefits of this scheme and continue its encouraging start.

There is one important caveat to the above - for the time being at least: the names of new prokaryotic taxa 
are not validly published until the paper appears in print; this is due to Rule 25a of the Bacteriological Code, which states that 'Effective publication is effected under this Code by making generally available, by sale or distribution, to the scientific community, printed material for the purpose of providing a permanent record'. This Rule may well be revised to take account of electronic publication and developments in electronic archiving, as the Botanical and Zoological Codes have, at the forthcoming IUMS Congress in Paris (27 July-1 August 2002).

\section{Supplementary data and Notes}

Other efforts that we are making to shorten and enhance papers include the use of the supplementary data system in IJSEM Online - this allows full datasets, high-resolution images and full phylogenetic trees, for example, to be appended to the paper; we even have a freeware computer program called FreeTree appended to one paper - see the paper by Hampl et al. in the May 2001 issue. I should take this opportunity to reiterate that it is SGM's policy that supplementary data will be maintained in perpetuity and be freely available without an institutional subscription. The Editors are also attempting to get authors to convert full papers to the Note format (especially for the description of a single new species), again with the aim of publishing more papers within a given page limit. Naturally, this has met with resistance in some quarters! Of course, it is much more straightforward if authors submit Notes in the first place. In the light of what I said above, it would be good for the journal and the community of systematists that it serves if authors keep economy of word, table and figure in mind when writing papers. This should not detract from the scientific quality of papers.

\section{Full-text HTML in IJSEM Online}

With publication of the current issue, we have introduced full-text HTML to IJSEM Online. This enables major improvements to the online journal, especially full-text searchability and inter-article linking via the CrossRef scheme, a collaborative venture between journal publishers that enables seamless linking between thousands of participating journals. Of course, PDF reprints will still be available for printing and reading away from the computer screen.

\section{Editorial Office changes}

There have also been some developments in the Editorial Office - Dr Robin Dunford has been promoted to Deputy Managing Editor from his position on the Journal of General Virology, and we have recently upgraded our IT systems to cope with all the technological developments mentioned above. We aim to continue to provide a high level of service to our readers and authors, and will continue to enhance the journal in light of developments in the fast-moving world of journal publishing. 